\title{
El PAISAJE CULTURAL COMO ELEMENTO DE PATRIMONIALIZACIÓN: el caso de Vega de Pas, Cantabria, España ${ }^{1}$
}

\author{
Jorge Magaña Ochoa \\ Belkis G. Rojas Trejo
}

Resumen: El presente artículo esboza algunos de los cambios histórico-sociales más importantes sufridos por la cultura pasiega (Vega de Pas), sobre todo a partir de la aplicación de las políticas económicas europeas que provocaron el declive y la pérdida de centralidad del trabajo ganadero. Con dichas politicas se pretende actualmente "integrar" a los pasiegos en un proceso de patrimonialización de su paisaje y de su cultura.

Palabras Clave: Pasiegos, cultura, patrimonio, paisaje, ganadero.

Enviado a dictamen: 06 de diciembre de 2007. Aprobación: 04 de marzo de 2008

Jorge Magaña Ochoa, candidato a doctor por la Universidad de Sevilla, España, profesor-investigador de la Universidad Autónoma de Chiapas, México, especialización en antropología médica, correo electrónico: jorgem41@hotmail.com. Belkis G. Rojas Trejo, candidata a doctora por la Universidad de Sevilla, España, profesora-investigadora de la Universidad de Los Andes, Mérida, Venezuela, especialización en etnohistoria y antropología social, correo electró nico:bgrojas@hotmail.com.
Abstract: This paper outlines some of the most significant cultural changes experienced by the pasiego peoples, Vega de Pas, mainly as a result of the implantation of European economic policies, which are causing the collapse of the cattle breeding industry and the consequent loss of its central role, these policies are seeking, instead, to turn the pasiego landscape and culture into a national patrimony.

Key words: Pasiego peoples, culture, patrimony, cattle breeder.

\section{Introducción}

$\mathrm{H}$ ablar o pensar desde la antropología en la recuperación de lo local y sus implicaciones es poner el acento, como diría Eduardo Menéndez, en lo simbólico "y en los procesos de reinterpretación y resignificación local de lo general que, entre otras cosas, está implicando la recuperación de los conceptos de difusión y aculturación, de las resistencias culturales locales a lo global, del relativismo sociocultural, etcétera" (Menéndez, 2002: 153).

Por tal motivo, la reflexión aquí presentada trata de introducirnos en un mundo sobre el que se han construido un sinfín de mitos originarios y del que todavía se sigue buscando, con asiduidad y hasta con necedad, su ascendencia mora, judía, indoeuropea, visigoda o cántabra, sin importar que cada día transcurrido trabaja 
contra su existencia; es decir, actualmente es un pueblo que vive un claro proceso de desintegración y hasta desaparición. Existe un cierto interés por parte de las instituciones de preservar, a través de la aplicación de políticas de anclaje y recuperación cultural con intenciones patrimoniales, políticas que son aprovechadas por intereses privados con intenciones subterráneas de obtener beneficios, como consecuencia de la casi nula intención que se tiene para elaborar y poner en marcha estrategias que conduzcan a una sanción social legitimadora por parte de los pasiegos y pasiegas del pueblo y de sus barrios.

Este artículo, más que buscar un debate sobre patrimonialización pretende mostrar los elementos que han construido y estructurado una cultura a través de los siglos y que en la actualidad se han vuelto fundamentales para su desintegración con fines empresariales ajenos o externos a la comunidad. Es decir, la comunidad que otrora fue núcleo de desarrollo ganadero importante, hoy trata de sobrevivir con lo que hay: subvenciones, jubilados, viejos y jóvenes que emigran. Algunos de sus habitantes están empeñados en una lucha desigual con un destino inexorable, tratando de preservar algo de las antiguas glorias de la localidad.

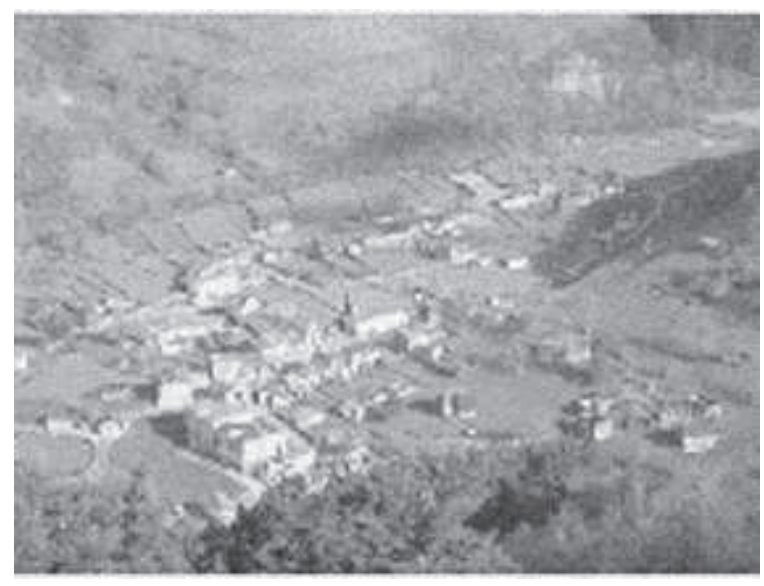

Imagen del casco-pueblo de Vega de Pas
Vega de Pas es lugar de nostalgias y encuentros, capital de un municipio montañoso que ha sobrevivido a largos años de competencia ganadera, pero que con el arribo de una nueva generación desmemoriada, ha visto tocar el fin de su auge.

En la localidad se nota claramente un entrecruzamiento de mundos de diferente significación y la pugna por establecer la hegemonía de las explicaciones sobre el origen y construcción cultural, en cuyo centro aparece el paisaje como elemento fundamental. Esta pugna se vuelve el objeto de una lucha simbólica. Las distintas interpretaciones son oponentes desiguales y el capital empresarial busca sacar el mejor provecho, como por ejemplo, de la búsqueda de reconocimiento de la patrimonialización del paisaje pasiego. Por ello, dicho capital se apoya en las propuestas del Colegio de Arquitectos de Cantabria para que el paisaje pasiego sea declarado Patrimonio de la $\mathrm{Hu}$ manidad, pues se considera que la formación históricocultural del paisaje de prados sembrados con cabañas de piedra y techos de laja, los particulares, cercados de piedra seca, son un modelo casi único y diferenciador de la cultura pasiega, caracterizada por ser ganadera.

Para comprender este proceso, en el presente artículo haremos, en primer lugar, una breve revisión de la formación histórica del paisaje cultural pasiego, para luegoubicar a Vega de Pas tanto desdeel punto de vista geográfico como en su situación socioeconómica y demográfica actual, lo cual ayuda en la comprensión de su transformación y de la puesta en marcha de una opción patrimonializadora, tanto del paisaje como de otros elementos de la cultura. Por último, planteamos algunas reflexiones en torno a las nuevas "propuestas" para el logro del desarrollo y la permanencia del pueblo y de sus pobladores, como lo es el turismo y su necesidad de patrimonializar.

\section{Construcción histórica del paisaje ganadero}

Al parecer, después de la reconquista ibérica (siglos IX al XV), junto a la repoblación peninsular se produjo una colonización de territorios sin titularidad jurídica, 
las denominadas tierras de nadie, lo cual hizo posible que los campesinos sin tierras accedieran a ellas bajo condiciones de vasallaje. Esto originó el surgimiento de pequeñas aldeas alrededor de los cursos de los valles fluviales y comunidades monásticas que suponían gran actividad colonizadora, la cual alcanzó a los Montes de Pas, territorio agreste que hasta entonces había estado en el olvido (Leal, 1991a; Flores, 2003).

Los estudiosos de la zona señalan que uno de los primeros documentos escritos que hace referencia a los Montes de Pas data del año 1011; ahí se alude a una donación hecha por el conde Don Sancho García y su esposa Doña Urraca al Monasterio de San Salvador de Oña, en Burgos. Los bienes cedidos al Monasterio incluyeron tierras, villas, iglesias, monasterios, vasallos y siervos de Castilla, de Santander, de Navarra y La Rioja, además de las pertinentes exenciones de impuestos a todo ello. Entre estas propiedades estaban los Montes de Pas, cuyos pastos debían ser aprovechados libremente por los ganados pertenecientes al Monasterio. Allí, señala Gonzalo Oceja (1983), fueron enviados un grupo de siervos casatos o rurales. Esto no significa, como señala Terán (Tax Freeman; 1979), que los Montes estuvieran deshabitados antes del año 1011, pero no contaban con pueblos y villas independientes, aunque no se han encontrado documentos que evidencien la existencia de asentamientos antes de esta fecha y en cambio, en un documento de confirmación de los derechos de pasto concedidos por Enrique IV el Doliente en 1467, los Montes fueron descritos como "montañas yermas, montañas bravas y desiertas" (Tax Freeman, 1979; Leal, 1991b).

Esta marcada dureza y bravura de los Montes de Pas es un factor que, sin caer en determinismos o romanticismos, debemos tener en cuenta a la hora de entender la formación histórica y cultural de los pasiegos, pues dicho territorio ha sido transformado por ellos en la misma medida en que fueron conformando un tipo de vida, unas técnicas de trabajo de explotación ganadera y una colonización y ordenación del espacio para el desarrollo del mismo. En el Privilegio de Villazgo de 1689, estudiado cuidadosamente por Leal (1991a), cuando se habla de las tres villas pasiegas se añade seguidamente Montes de Pas, con lo cual se quiso señalar a un territorio marcadamente desigual y accidentado. Esto llevó a Leal a mostrarse de acuerdo con Manuel de Terán cuando afirmó que "los Montes de Pas constituyen una comarca geográfica cuya personalidad y delimitación depende en mayor grado de las condiciones humanas que de los factores físicos" (Terán, 1947: 10). Actualmente, los ecólogos también afirman que no existen paisajes naturales en los Montes de Pas, si por esto se entiende que la intervención humana no ha cambiado significativamente sus rasgos y cualidades originarias; aquí se habla de paisajes naturales antropizados, cuyos resultados más visibles son la vegetación, con los prados como elemento principal y el tipo de hábitat (Delgado Viñas, 2003).

La historia de los pasiegos va muy unida con la de Espinosa de los Monteros. De hecho, los Montes de Pas fueron considerados una extensión de Espinosa. Durante los cinco siglos siguientes a la donación del año 1011, los Montes de Pas carecieron de parroquias, sus habitantes recibían los sacramentos y eran enterrados en Espinosa, muy probablemente hasta bien avanzado el siglo XVII. Tal como señala Flores (2003), siguiendo a García-Lomas (1986), la adscripción jurídica del año 1011 fue la primera de una larga trayectoria institucional de las tierras pasiegas, que les haría rendir obediencia y pagar impuestos ante la villa de Espinosa de los Monteros desde 1396, y a la villa de Carriedo desde 1648, antes de poder comprar la independencia de las tres villas. A partir de dicha compra, que se hace efectiva en 1689, los pueblos pasiegos lograron convertirse, por real decreto, en villas independientes y se contempló que mantendrían en posesión cualquier comunidad de pasto que hubieran gozado previamente (Tax Freeman, 1979).

La presión demográfica del siglo XVII enfrentó a las comunidades de pastores pasiegos con otra decisión de gran importancia ya que, ante un mandato real de nueva ordenación territorial a favor de la roturación de tierras para promover la agricultura cerealista, 
El Paisaje CUlTural COMO ELEMENTO DE

debieron buscar salidas que protegieran su sistema de trabajo ganadero. La solución la encontraron en la aceleración del parcelado del valle y en la personalización de la propiedad de las fincas que ya se venía perfilando desde el siglo XVI. Así se fue desarrollando, hasta principios del siglo XX, el proceso de prados cerrados sobre sí (Ortega Valcárcel, 1975; Flores, 2003). Estos prados caracterizan el actual paisaje intensamente humanizado e implican el abandono del pastoreo extensivo para poner en práctica una forma de ganadería semiestabulada, lo que a su vez obliga a la intensificación del cultivo de los prados naturales con el fin de incrementar la producción; a limitar paulatinamente la heterogeneidad de los rebaños; y a la especialización de la ganadería vacuna. Esta forma de aprovechamiento ganadero constituyó la base de la economía campesina como un pujante factor de comercialización. Buena parte de los productos derivados de las explotaciones ganaderas fue destinada al mercado y complementada con algunos derivados de la cría menor de aves, porcinos, ovinos, caprinos, además de la elaboración de algunos productos artesanales, como mantas de lana, cuévanos ${ }^{2}$ y almadreñas, ${ }^{3}$ muy utilizados y de mucha demanda en la zona para la realización de faenas de campo y otras actividades de la vida cotidiana.

A finales del siglo XIX y durante las primeras décadas del siglo XX, aumentó la demanda de productos lácteos y leche fresca desde los centros urbanos, lo cual obligó a los pasiegos a realizar un nuevo cambio: sustituir la raza de ganado local, la "vaca pasiega" (que además se extingue en el siglo XX), por ganado de la raza holstein-frisian. La vaca pasiega era muy valorada por su leche, aunque daba poca era muy apreciada por su alto porcentaje ( $8 \%$ ) de materia grasa, lo cual era muy importante para la elaboración artesanal de mantequilla y quesos que se destinaban al mercado y constituía una de las actividades económicas significativas para los pasiegos. Pero la vaca frisian triplicaba y hasta cuadruplicaba la producción lechera y la base de grasa actual es de 3.8 a $4 \%$.
La sustitución modificó el sistema productivo ganadero, que no contemplaba la cría de ganado para la venta sinola obtención de leche para consumo humano, asícomo alimentar a los terneros, elaborar quesos y mantequillas que se destinaban al mercado. En contadas ocasiones se vendía alguna vaca para obtener otros recursos.

Después de la sustitución esta tendencia cambió y se fue orientando paulatinamente hacia la recría de ganado de aptitud lechera para su posterior venta a otras explotaciones o en las ferias ganaderas (que en la actualidad han desaparecido), y se mantiene la producción de derivados lácteos, fundamentalmente la mantequilla. Esta especialización del ganado ha traído un cambio en el paisaje, producido por la desaparición de los cultivos y la deforestación de los montes, ahora destinados a incrementar los prados para cubrir las necesidades del aumento de cabezas de ganado, así como una forma más compleja de aprovechamiento de los pastos, incorporando a la práctica de los desplazamientos del ganado en sentido vertical, impuesta por las condiciones del clima y del terreno, un desplazamiento horizontal.

A partir de la década de los sesenta, la tendencia a la recría de ganado de aptitud lechera se fue complementando con la producción y comercialización de leche destinada a las industrias (Tax, 1979; Ibáñez, 1990; Delgado, 2003,).

Como se puede observar en este apretado recorrido, la construcción histórica de los paisajes pasiegos debe entenderse estrechamente relacionada con sus procesos de producción y las formas de trabajo que atañen pues, como señala Narotzki, el medio ambiente siempre es producto de los procesos sociales e históricos y, "para las poblaciones humanas, el espacio no es tanto un hecho material y objetivo determinado como una experiencia vivida" (2004: 25). En este sentido, la apariencia actual de los paisajes pasiegos es un producto directo de la intervención de sus habitantes debido a las actividades productivas ganaderas, fundamentalmente la trashumancia estacional, la construcción y formas de uso de las cabañas y la producción de pastos, entre otras. 


\section{El municipio de Vega de Pas}

Lo que se conoce como la región pasiega incluye no sólo el valle del río Pas, sino otros valles colindantes: los conformados por los ríos Miera y Pisueña, con los que comparte las características que construyen lo que se ha dado en llamar identidad pasiega. Una de las causas de su singularidad, en lo que se refiere al paisaje, es la presencia de montañas y laderas y la abundancia de lluvias, más que en ningún otro lugar de Cantabria, considerada, además, como una de las zonas más lluviosas de España, con registros que superan los dos mil litros anuales de precipitación con copiosas nevadas invernales. Estas características insertan a la comarca pasiega en el propio corazón de la denominada "España Verde", pero ha sido el aislamiento, que durante muchos siglos afectó a sus habitantes por las características de las montañas presentes en este valle apartadas de las principales vías de comunicación, lo que ha condicionado la forma de vida de sus pobladores, con peculiaridades que despiertan el interés de diversos estudiosos (Flores, 2003).

El Valle de Pas es un territorio comprendido en la comarca conocida con el nombre de Los Montes de Pas (de una extensión territorial de $444 \mathrm{Km}^{2}$ ), ubicado en el sector central y meridional de la Comunidad Autónoma de Cantabria. Este territorio conforma un espacio de montaña media perteneciente a la cordillera cantábrica, con una sucesión de sierras, interfluvios y valles, del que el Pas (valle y río) forma parte. Actualmente esta comarca comprende los municipios de Luena, Miera, Ruesga, San Pedro del Romeral, San Roque de Riomiera, Saro, Selaya, Vega de Pas, Villacarriedo y Villafufre, así como los ríos Pas, Miera y Pisueña.

Los Montes de Pas son un confín administrativo, al servir de frontera natural entre la Comunidad Autónoma de Cantabria y la Comunidad Autónoma de Castilla y León, hace de divisoria de aguas entre la vertiente mediterránea y la cantábrica. Su cordillera corresponde a costas comprendidas entre mil doscientos y mil setecientos metros sobre el nivel del mar (msnm) (Flores, 2003).
El Pas, río que da vida a este valle, junto con todos sus afluentes es un río de:"régimen pluvio-nival por recoger las aguas de zonas más amplias y a mayor altura de toda la vertiente cantábrica desde Mediajo Frío hasta Castro Valnera, donde la nieve puede durar de noviembre a marzo casi continuamente, de ahí que los máximos se registren en invierno y, sobre todo, en primavera, cuando tiene lugar el deshielo, después de un periodo de menores caudales entre febrero y marzo debido a que la nieve está presente en las áreas altas con mayor asiduidad y, por tanto, la escorrentía superficial menor [...] Estos elementos de origen fluvial son los encargados de generar los aluviones y las terrazas tan características de la zona, los detalles de sus laderas, cársticos y glaciares (Flores, 2003: 45).

El río Pas, por último, nace en el área comprendida entre el Pico del Haya, a 1,265 msnm, y El Coterón, a 1268 msnm, ubicados en el macizo montañoso denominado las Estacas de Trueba, y sale del valle a la altura del poblado de Estrambasmestas. Este río, durante su recorrido, recoge los caudales de numerosos afluentes de cierta importancia, los arroyos de Pandillo, Yera, Viaña, Barcelada, Troja, Aldano; y el río Magdalena, que es el principal colector del valle de Luena; y el de La Plata, que desemboca por el Soto en el valle de Toranzo (Flores, 2003: riancha.http:/centro3.pntie.mec.es).

El municipio de Vega de Pas, por tanto, se encuentra ubicado en el Valle del Pas, en el extremo sureste de Cantabria, colindando con el municipio de Salcedillo de la provincia de Burgos, y formando parte de la antigua jurisdicción de los Montes de Pas. Tiene una extensión de $87.6 \mathrm{Km}^{2}$, lo que lo acredita como uno de los más grandes de Europa en cuanto a extensión territorial, y se encuentra rodeado por los municipios de San Roque de Riomiera, Selaya y Villacarriedo, por el norte; Luena, por el oeste; y San Pedro del Romeral, por el suroeste. Sus habitantes se distribuyen en siete núcleos poblacionales: un casco-pueblo, como le llaman los pasiegos a su capital Vega de Pas, que es a su vez 
El paisaje CUltural COMO ELEMENTO DE

el núcleo con mayor población del municipio; y seis barrios, como se denominan a las poblaciones rurales de Vega, que son: Candolías, La Gurueba, Guzparras, Pandillo, Viaña y Yera.

\section{Estructura sociodemográfica de Vega de Pas}

Desde mediados del siglo pasado, en Vega de Pas se ha manifestado, como un fenómeno constante de evolución demográfica, la disminución progresiva de habitantes. A lo largo del siglo Xx y hasta la actualidad, su población se ha reducido en 53\%, pasando de los 2066 habitantes registrados en 1900, a 969 vecinos empadronados en 2003 (INE, Censos de Población, 2000-2003). El decrecimiento poblacional afecta a las otras villas pasiegas y a casi toda la comarca Pas-Pisueña, que desde 1960 hasta la actualidad ha tendido a disminuir su población.

El fenómeno migratorio interno y externo que ha vivido Vega de Pas afectó a toda España a lo largo del siglo XX, y ha estado íntimamente ligado con condicionamientos económicos y políticos. De manera especial, los movimientos migratorios interiores producidos desde finales de los años cincuenta están estrechamente relacionados con el proceso de industrialización de ciertas regiones españolas y constituyen, a su vez, una emigración laboral y una redistribución de la población activa, entre la agricultura, la industria y los servicios. En estos años y durante el primer quinquenio de los setenta se ha producido un ingente éxodo rural junto con la consolidación de los más importantes centros urbanos industriales y la aparición de otros nuevos. Las comunidades con potencial económico y laboral mayor se convirtieron en centros receptores; por ejemplo, Madrid, Cataluña, el País Vasco y, en menor medida, Valencia, Baleares, Zaragoza y Valladolid (Naredo, 2004).

Los pasiegos manifiestan que la llamada "modernidad" ha traído la despoblación:

La gente se ha ido, muchos no volvieron, las mujeres se van y no regresan; las que se quedan y se casan aquí tie- nen muy pocos hijos y los hombres, muchos estamos solteros, no hay mujeres aquí para formar familia, se acaban las familias y se acaba el campo, ya le quieren muy pocos, los viejos (Lolo, Vega de Pas, 2006).

Antes estos barrios estaban muy poblados porque las familias eran muy grandes, muy numerosas, las familias eran de diez, once personas isabes? Sin embargo eso ahora se ha perdido y la mayor despoblación viene por eso también, claro, porque las familias han disminuido mucho. Pandillo era la zona más poblada, pero ahora ya es que vive poca gente en todos lados (Pablo, 2005).

Delfi señala que la vida moderna acarreó el abandono del campo por su poca rentabilidad en estos tiempos:
Ahora ya la gente pues se ha modernizao y el campo ya no le quiere nadie tampoco, que no, para el campo quedan pocos, el que puede irse a ganar un jornal por pequeño que sea pues se va a trabajar a 'onde sea, aunque tenga qué dejarse el sueldo en la carretera en gasolina y en comer y algunos que luego vienen por la tarde y les gusta el chupiteo y el cubalibre pues allá andará si sacan $p a^{\prime}$ ello, pero lo prefieren que estar en el campo (Delfi, 2005).

Lo anterior se evidencia por el descenso de la natalidad y el estancamiento de las tasas de mortandad, como consecuencia del progresivo envejecimiento poblacional. Las defunciones en la comarca pasiega son superiores a los nacimientos y, al no ser municipios de inmigración sino de emigración, la población cada día se vuelve más vieja. Éstos son los factores que han determinado este detrimento y han dado lugar a que el perfil demográfico de Vega de Pas sea predominantemente adulto, pues este grupo de edad representa $64.5 \%$ de la población total, mientras los jóvenes suponen $13.4 \%$ y los viejos $22.2 \%$. El índice de envejecimiento, por consiguiente, es 165.9\% y la edad media 42,8 años (INE, Censos de población, 2001).

Según el Censo de Población de 2001, la población del municipio se encuentra distribuida así: el pueblo de 
Vega de Pas, capital del municipio, ubicado a 358 msnm constituye el mayor centro poblado, con 309 habitantes. Y los barrios Candolías, Guzparras, La Gurueba, Pandillo, Viañay Yera, presentan la siguiente perspectiva poblacional: Candolías se encuentra a una distancia de $1.3 \mathrm{~km}$ de la capital de Vega (es el barrio más cercano a ésta) según el censo de 2001 se encuentra habitado por 138 personas; Guzparras es el núcleo actualmente más pequeño del municipio, con sólo 20 vecinos y es el barrio más distante de la capital a 7 km; La Gurueba, en el extremo oeste del municipio, a 241 metros de altitud, se encuentra a una distancia de $5 \mathrm{~km}$ de la capital y cuenta con 93 habitantes; el barrio Pandillo, en el extremo noreste del municipio, a $3.5 \mathrm{~km}$ de Vega de Pas, es el barrio más importante desde el punto de vista demográfico después de la capital, con 193 habitantes. Por último tenemos los barrios de Viaña y Yera; el primero cuenta con 69 vecinos y está a $3 \mathrm{~km}$ del pueblo; Yera, con 147 personas, se encuentra a $2.5 \mathrm{~km}$ de la capital del municipio y a $569 \mathrm{msnm}$.

\section{Características socioeconómicas}

A pesar del profundo despoblamiento y el paulatino abandono del campo, cada vez más notorio sobre todo por el olvido de caminos, prados y cabañas de las alturas, Vega de Pas sigue siendo predominantemente un municipio ganadero. El mayor peso de su estructura productiva recae en el sector primario, es decir en la explotación ganadera. Para el 2001 cerca de 44\% de su población se ocupa de ella, en casi toda la superficie de Vega aún explotable como propiedad privada. Esta situación se refleja en el siguiente cuadro, elaborado a partir de los datos del Censo Agrario de 1999:

\section{Actividad agraria. Datos generales}

\begin{tabular}{|c|c|c|c|}
\hline $\begin{array}{c}\text { número de } \\
\text { exploraciones }\end{array}$ & $\begin{array}{c}\text { superficie total } \\
\text { (ha) }\end{array}$ & SAU (13) (Ha) & $\begin{array}{c}\text { número de } \\
\text { parcelas }\end{array}$ \\
\hline \hline 156 & $7,558.13$ & $7,237.60$ & 871 \\
\hline
\end{tabular}

Fuente: INE, Censo Agrario, 1999.
Sin embargo, debemos aclarar que nuestro trabajo de campo nos indica la posibilidad de que ese $44.2 \%$ de ocupados en la ganadería en 2001 sea menor a finales de 2005. En el transcurso de este año hemos podido constatar el cese total del trabajo ganadero de por lo menos seis familias que aducen, como razones fundamentales, la baja rentabilidad y, debido a que los hombres deben salir a trabajar fuera del pueblo como obreros en la construcción, el grueso del trabajo recae sobre las mujeres y es muy duro. Por tanto, hoy el esfuerzo de estas personas está dirigido a la desesperada búsqueda de compradores para sus cabañas y así a su vez, puedan comprar un piso o casa en el pueblo o en otro pueblo cercano. Esta urgencia se traduce en las palabras de Gervasio:

Tengo alguna cabaña allí arriba (se refiere a su barrio Pandillo) que las quería vender ahora. Que ahora hay que venderlas en lo que se pueda, hay que sacar las perras de onde sea, tengo comprada esa casa de la Calle Atrás, ahora hay que pagala pa' quedarme ya ahí, icon tantos años pa' dónde vas a ir? (Gervasio, 2005).

En los últimos años se ha notado un incremento sensible del sector servicios, al que se dedica $30.4 \%$ de la población actual, sobre todo porque hay una experiencia acumulada en este sector desde los años sesenta. Vega de Pas también fue tocado por el denominado "boom español" de esos años: el desarrollismo y la extensión del turismo como fuente destacada de ingresos. Sin embargo, esta es una actividad que involucra fundamentalmente a las personas que viven en el pueblo y ya tienen esa experiencia, aunque también hay que reconocer que genera algunos empleos para los pobladores, sobre todo para las mujeres que viven en los barrios.

Por último, la industria se encuentra poco desarrollada y difundida en Vega de Pas, y se aboca más a la elaboración de productos lácteos ${ }^{4}$ y a cuatro de las más famosas empresas artesanales de la región elaboradoras de sobaos y quesadas: "Sobaos Ortiz", "La Zapita", "Re- 
El paisaje Cultural COMO ELEMENTO dE

PATRIMONIALIZACIÓN: El CASO DE VEGA DE PAS,

vueltas" y "Serafina" (con fábricas incluso en México). Esta actividad representa una ocupación de 10.8\% de la población activa.

Un dato interesante es el aumento de la población económicamente activa ocupada en la construcción, la cual emplea actualmente $14.6 \%$ de la población joven masculina: "los jóvenes migran a la ciudad, los jóvenes se van a trabajar a la construcción porque aquí en España eso es un boom y deja mejor que andar detrás de las vacas, ellos ya no quieren estar como sus papás con lo de las vacas. Ya no es rentable" (Pablo, 2005).

La realidad de Vega de Pas se encuentra, en losúltimos años, en un proceso de cambio profundo con tintes contradictorios, en algunos casos afecta no sólo el estilo de vida sino la estructura productiva. Cambios importantes de tomarse en cuenta en los que el sector agrario está cediendo paso a otro tipo de actividades económicas como el trabajo en la construcción y el sector servicios.

\section{Transformaciones: turismo y patrimonialización}

Los procesos de cambio estructural (políticos, económicos y socioculturales) que conforman la actual España y que se pueden observar a través, por ejemplo, del establecimiento de la democracia y el fin del franquismo o el ingreso de España a la Unión Europea, han provocado otra forma de entender o comprender la vida social y productiva de los pueblos españoles, y sobre todo del que nos ocupa. Ya no son tiempos del enfoque de la comunidad cerrada para hablar de la pasieguería, en que no sólo la identidad, sino las actividades políticas, económicas y culturales se suponían circunscritas al ámbito comunitario.

El aislamiento y la forma de vida trashumante contribuyeron a la creación de una serie de mitos y estereotipos en torno a los pasiegos y a su cultura, difundidos por la imaginería poética decimonónica, como señala Godelier: "las creencias surgen de lo imaginario" (1998, 47). Mitos y creencias versaban más que nada en ese estilo de vida trashumante y en un proceso de trabajo basado en la "muda" estacional tanto del ganado como de la familia ganadera, que implicaba que gente y ganado compartieran un mismo espacio de vida cotidiana.

Actualmente, ante los nuevos programas y políticas económicas de la Unión Europea para el desarrollo estructural de los pueblos y estados europeos, nos encontramos en la disyuntiva de que determinados pueblos, grupos humanos o formas de vida se hayan ido excluyendo del mercado común por no coincidir con las propuestas desarrollistas de éste; o que dichas propuestas hayan sido consideradas, por los afectados, como un obstáculo para el desarrollo de sus pueblos. Un ejemplo es precisamente lo que sucede con los pasiegos: a pesar de un aparente proceso de inclusión, o mejor dicho de integración a las nuevas propuestas de desarrollo planteadas por el sistema económico global dominante, se les ha ido excluyendo y se han visto amenazados en su extinción grupal o sociocultural:

¿Sabremos quién manda en realidad? Yo no entiendo, poco a poco, llevan muchos años, llevan ya 15 ó 20 años, venga, venga y venga, caña y caña con los ganaderos y desaparecen los pueblos, desaparecen. Bueno, eso la gente los que más o menos venís por ahí los podéis ver mejor que nosotros y a la vuelta de diez años no habrá nadie, nada más hay que darse cuenta que más o menos la gente que hay en el campo de cuarenta pa'lante pocos ya, de treinta pa'tras ya no queda ninguno prácticamente, pues a la vuelta de diez años no queda nadie. Eso son políticas que hacen los gobiernos, eso está más claro que el agua, yo qué sé, o son intercambios que hacen de cosas, no lo sé, porque yo eso no lo entiendo (José, Torrelavega, 2005).

El tema de la ganadería ha ido desapareciendo principalmente por la entrada de España en la Comunidad Económica Europea, como son zonas consideradas de alta montaña no se reúnen las condiciones para una producción de leche óptima. No es óptima para la comunidad, para el Mercado Común (Pablo, 2005). 
Estamos frente a un pueblo presa del mundo moderno, abrumado por una asimilación violenta al mismo, sin haber tenido tiempo para comprender a cabalidad el imperativo de cambio en su forma de vida, a pesar de que muchos de sus habitantes se han incorporado a la carrera que implica dicho cambio e intentan cumplir con las nuevas exigencias nacionales e internacionales impuestas por la Unión Europea. Su finalidad es mantenerse como ganaderos; para ellos este modo de vida es su fuente de sentido y experiencia, como diría Manuel Castells (2003: 34) y, como muchos de ellos afirman, "vivir de las vacas y no para las vacas". Este propósito implica el abandono de las formas "tradicionales de producción" y la modernización de la actividad ganadera. Ellos están conscientes, sin embargo, no se cuenta con la infraestructura necesaria exigida por el mundo capitalista para la continuidad y rentabilidad del trabajo ganadero en un pueblo de alta montaña como Vega de Pas. Un pueblo que, como ya hemos visto, en los últimos 40 años ha vivido un acelerado proceso despoblacional, causado por las emigraciones de sus jóvenes y que ha sido sometido a un cambio de aislamiento a desintegración. Como diría Menéndez:

Los principales cambios que se desarrollan a nivel local [...] generados [...] por la expansión económicopolítica e ideológica que ahora llaman globalización, [...] modifica las opciones y ataduras locales, incluyendo las estrategias defensivas y/o de resistencia de los sujetos locales (Menéndez, 2002: 153).

Actualmente los pasiegos no son los ganaderos de antaño o los que siempre fueron: "Las categorías de percepción del mundo social y de los grupos construidos según esas categorías se construyen a su vez en las luchas que constituyen la historia del mundo social" (Bourdieu, 1999: 102); en este caso una lucha marcada por la necesidad generacional de integrarse en la modernidad y dejar a un lado estilos de vida percibidos ahora como atrasados y poco rentables.
En resumen, estamos ante un pueblo que, parafraseando a Anthony Giddens, ha quedado secuestrado por la modernidad:

El tiempo de vida se separa de la exterioridad del lugar en tanto que éste es socavado por la expansión de los mecanismos de desenclave. En la mayoría de las culturas tradicionales la mayor parte de la vida social estaba localizada, a pesar de las migraciones de pueblos, relativamente frecuentes, y de las largas distancias que algunos pocos recorrían en sus viajes (Giddens, 1995: 188).

Como ejemplo tenemos el caso de Antonio quien, pese a permanecer (como muchos pasiegos por necesidades económicas) alrededor de nueve años trabajando como heladero ${ }^{5}$ en Ammiens, Francia, no ha perdido su identidad pasiega. Antonio se adhirió a las redes sociales construidas por los pasiegos en el territorio francés, donde él y los demás pasiegos no se integran (pero tampoco pretenden hacerlo) a la cultura del medio que los cobija, pues siempre tienen en la mira regresar al pueblo de origen. Algo que sólo algunos pudieron lograr.

Con los hijos de los pasiegos es distinto. Su pueblo se convierte en presa de las transformaciones de la modernidad sin darles espacio para reflexionar sobre ello, mientras se amplía la ruptura generacional cultural con sus padres. Si seguimos a Giddens:

El factor primordial que ha alterado esta situación reside en el aumento de la movilidad; el lugar ha quedado, más bien, invadido por mecanismos de desenclave que recombinan las actividades locales en relaciones espaciotemporales de ámbito cada vez más amplio (Giddens, 1995: 188).

Esta modernidad también ha generado mitos en torno a este tipo de pueblos, que van desde considerarlos pueblos malditos, ${ }^{6}$ cerrados, violentos, holgazanes, sin interés por el cambio de vida (entendida ésta a partir de la mejora 
El paisaje Cultural COMO ELEMENTO dE

PATRIMONIALIZACIÓN: El CASO DE VEGA DE PAS,

en "lo que tengo sin importar tanto lo que soy"), hasta hacerles pensar e introyectar las consecuencias de estas ideas: "A los pasiegos o nos quieren o nos odian pero no existen términos medios”, es un comentario común en Vega de Pas. En este sentido, "el tiempo de vida se libera cada vez más de las referencias externas asociadas a los lazos preestablecidos con otros individuos y grupos" (Giddens, 1995: 188). Siguiendo con Giddens, la tendencia a la modernidad no es otra cosa que la tendencia "hacia el control, por lo que respecta a la reproducción social y a la identidad del yo," (teniendo) "ciertas consecuencias características en el plano de la experiencia moral", este autor denomina a esta experiencia moral como "experiencia secuestrada" (...)" fenómeno (...) directamente ligado al carácter internamente referencial de la vida social y el yo" (Giddens, 1995: 188 y 191).

Por otro lado es preciso tener presente que los procesos de desarrollo y transformación sociocultural, incluyendo los movimientos poblacionales y cambios demográficos, impactan de manera contundente en la población, generando o dando cabida a toda una imposición de prácticas que obedecen a una estructura de poder hegemónica y globalizada. Es decir, en contextos locales complejos y en procesos de profunda y desigual transformación ${ }^{7}$ económico-social, ipodemos comerciar con la identidad sociocultural de un pueblo, utilizando para ello el pretexto de la patrimonialización en bien de la humanidad? Estamos hablando, no lo olvidemos, de un complejo local sociocultural inmerso en un fenómeno de violenta transformación hacia la modernidad y en el que se deben comprender las nuevas correlaciones y configuraciones de relaciones sociales (económicas, sociales y culturales) que conforman este territorio.

Sin embargo, al considerar lo local se debe tener cuidado,de no confundir esta dimensión local con la actuación del sujeto en su cotidianidad exclusivamente; y de no quedarse sólo en la búsqueda de regularidades y patrones socioculturales sin tomar en cuenta, a su vez, el papel del sujeto en la producción y reproducción de significados sociales y culturales tanto del contexto como los asimilados por el fenómeno de globalización. Gran parte de la configuración sociocultural de los pasiegos estaría determinando las posiciones y representaciones simbólico-sociales y de significado sobre las que entran en juego, ya sea a través de la negociación o del conflicto con otros actores sociales, modelos o estructuras de significación, en un contexto afectado por la asimilación y las demandas de la Unión Europea a la región de estudio. No debemos olvidar que se caracterizaron por ser productores de leche y de ganado de aptitud lechera y que la Unión Europea ha puesto serias normas y restricciones a la comercialización, afectando a las regiones de alta montaña.

Desde el fin del franquismo hasta la instauración de la vida democrática en España, es decir en los últimos 30 años, los pasiegos han vivido un proceso acelerado de violento cambio que amenaza las estructuras relativas de su cultura, es decir, la tradición de un estilo de vida y un proceso de producción que se remonta a casi diez siglos atrás y que se sigue, en algunos casos, reproduciendo hasta la fecha.

Aunque la explotación ganadera ha sido la base de la estructura productiva en Vega de Pas, en la actualidad la región atraviesa una situación de fragilidad y severa crisis, pues para la mayoría de los pasiegos ya no es una actividad redituable. Para ellos, gran parte de este cambio es consecuencia de la entrada de España en la Unión Europea, lo que impuso un sistema de cuotas que ha ido mermando tanto la producción de leche, como la cría de ganado:

Nos quitaron de vender leche, no podemos más. Porque aquí antes vendíamos leche, el que tenía diez litros como el que tenía cincuenta, como el que tenía cinco. Cada cual los litros que tenía ime entiendes? Bueno, pues ese era un medio de vida porque llegaba el mes y era como quien tiene un oficio y va a trabajar y al mes pues tiene un sueldo [...] y es lo que come; pues a nosotros nos pasaba igual. Ahora nos prohibieron. No podemos vender leche, no podemos vender nada (Pilar, 2005). 
O como menciona Gervasio Pelayo, de Barrio Pandillo:

Aquí no vale nada ya (se refiere al ganado), muy poco, muy poco, porque antes los macacos ${ }^{8}$, se vendían de puta madre, los corderos y eso. Hoy sí se venden pero muy poco, hay alguno que se vende así o a algún casero o tal, como de contrabando, pero vas a comprarlo a 1,300 pesetas el kilo y, joder, está bien que ganen pero no más que el que le cría, el que le cría había de cobrar un poco más que el intermediario (Gervasio, 2005).

Está claro que las sociedades locales no pueden quedar al margen de las condiciones globales que impone el sistema mundial. Señala Zamora:

Si los actos económicos no deben ser considerados unidireccionales, tampoco se puede obviar que no hay posibilidades de caminar a situaciones de mayor bienestar olvidando la importancia que tiene lo económico (Zamora, 1994: 10).

Los jóvenes han ido encontrando otros espacios de integración laboral y social, como la construcción, que según ellos les brinda mejores perspectivas de desarrollo individual; esta opción tiene relación directa con el hecho que el nivel educativo en Vega de Pas, presenta uno de los índices más bajos de la Comunidad Autónoma de Cantabria, por no decir de España, desfavoreciendo la participación de los pasiegos en otro tipo de actividades productivas más profesionalizadas y mejor remuneradas. Pablo Pelayo reflexiona al respecto:

¿Qué pasa?, pues que aquí sale gente que efectivamente no tiene cualificación ni empleo, pero hoy en la construcción gana mucho dinero, entonces la gente se ha ido repartiendo en la construcción; y pues prácticamente se ha quedado desierto el pueblo en ese aspecto, los más jóvenes, sobre todo los varones, se han ido a trabajar a la construcción, entonces la ganadería se ha quedado en manos de las mujeres que solas no pueden con ello (Pablo, 2005).

Pero es la actividad turística la que, en apariencia, se perfila como una solución a la crisis que representa la pérdida de centralidad del trabajo ganadero y de población. La política agraria de la Unión Europea propone, entre otras cosas, preservar y desarrollar el mundo rural con el fomento de una agricultura multifuncional, sostenible, competitiva, capaz de conservar el paisaje, de mantener el espacio natural, y contribuir de forma esencial a la vitalidad del mundo rural y responder a las preocupaciones y exigencias de los consumidores en calidad y seguridad alimentarias, de protección del medio ambiente y del bienestar de los animales. Lo paradójico es que son justamente las exigencias del mercado europeo unas de las causas principales, si no las principales, del abandono de la actividad ganadera en muchos pueblos de Cantabria y España, lo que trae el abandono de las superficies pratenses con, como señala Leonor de la Puente (2002), su consecuencia lógica: un nuevo cambio drástico del paisaje.

Desde este objetivo, los esfuerzos de la PAC para Cantabria y de la Consejería de Ganadería, Agricultura y Pesca del Gobierno de Cantabria, se han reflejado en las ayudas a los habitantes de los distintos pueblos (Vega de Pas entre ellos), con miras a la permanencia y desarrollo de la actividad ganadera. Dichos esfuerzos son parte fundamental de las apuestas al desarrollo de la región basadas en el turismo rural. En el caso del área pasiega se pone en juego un patrimonio edificado y un paisaje cultural engendrado a lo largo de mucho tiempo, unidos (y también productos de) a una actividad ganadera que conserva y revitaliza pero que, al parecer, sólo puede sobrevivir mediante formas de desarrollo sostenible que reorienten la vida de sus habitantes hacia nuevas actividades, las cuales casi de seguro quedarán supeditadas a los fenómenos turísticos.

Acorde con estas políticas se han implementado ayudas específicas para la consolidación o puesta en 
El paisaje Cultural COMO ELEMENTO dE

patrimonialización: el Caso de Vega de Pas,

marcha de la actividad turística a través del Programa Operativo de Desarrollo y Diversificación Económica de Zonas Rurales (Proder), presentado por el gobierno español ante la Comisión de las Comunidades Europeas, y aprobado el 18 de junio de 1996. Este Programa Operativo se encuadró en los ejes prioritarios número 2 (Desarrollo Local) y número 4 (Agricultura y Desarrollo Rural) del Marco Comunitario de Apoyo para las intervenciones estructurales en las regiones españolas del Objetivo 1, como el caso de la Comunidad Autónoma de Cantabria, ${ }^{9}$ donde comenzó a ser aplicado este mismo año en comarcas con problemas comunes: actividad agraria en declive, de alta montaña, con profundos procesos de emigración y envejecimiento de su población, sin una tradición industrial significativa, con una estética paisajística y con tradiciones culturales acordes a los deseos de explotación y "consumo de autenticidades" de la actividad turística.

Según análisis realizados por Delgado Viñas (1997), las acciones destinadas a impulsar el desarrollo turístico son las que han tenido mayor implantación en las comarcas de actuación del Proder en Cantabria. En el Pas integró a los municipios de Luena, San Pedro del Romeral, Vega de Pas, Puente Viesgo, Corvera de Toranzo y Santiurde de Toranzo, y al parecer su gestión fue poco satisfactoria en lo que se refiere a la distribución territorial de la inversión y de los proyectos. Los datos revelan que, además de no satisfacer el objetivo de diversificación por medidas, ha distribuido las ayudas en su área de actuación, de manera muy desigual, acentuando el peso en la rehabilitación o creación de establecimientos de carácter turístico, mientras que la atención a otras medidas fue insignificante, cuando no inexistente. En Vega de Pas la aplicación del Proder estuvo marcada por esta tendencia; las ayudas se decantaron en su mayoría hacia la rehabilitación y acondicionamiento de algunas viviendas ubicadas en el casco del pueblo, para su aprovechamiento como alojamientos turísticos.

A pesar del extraordinario potencial turístico del municipio de Vega de Pas, la afluencia de turistas es escasa y muy puntual; es una zona de turismo de paso o de permanencia corta y restringida a períodos de tiempo muy concretos: fines de semana y períodos vacacionales. La procedencia de turistas es básicamente regional y secundariamente nacional (especialmente de Madrid y del País Vasco, principalmente de Bilbao), siendo poco significativa la presencia de turismo extranjero, por lo que son turistas que en su gran mayoría gozan de vivienda propia en el lugar y es relativamente poco lo que gastan en el pueblo; sin embargo consumen en los bares y compran los productos de la industria de Vega como los sobaos y quesadas,,$^{10}$ lo cual ayuda al movimiento económico.

El fenómeno turístico ha generado un proceso de venta de cabañas en los distintos barrios que se ha convertido en una solución para muchos jubilados cuyos descendientes no se plantean seguir con el trabajo del ganado y ven con pena cómo sus prados y cabañas se pierden; esta venta también genera fuentes inmediatas de trabajo, sobre todo para los hombres en la construcción y en menor medida para mujeres en servicios domésticos. ${ }^{.1}$

En Vega el recurso de la naturaleza y de la cultura ganadera presupone la existencia de un producto turístico importante que se une a la existencia de una infraestructura de equipamientos y servicios (hospedajes, restaurantes, bares), de acceso (carreteras en buen estado) e infraestructura básica urbana (saneamiento, electricidad, comunicaciones). Sin embargo, mantener el turismo activo implica también que los atractivos deben ser renovados:

Los senderos hay que mantenerlos, antiguamente los senderos eran transitados por los ganaderos y el ganado, ahora como no los transitan pues se cierran porque aquí la vegetación es muy fuerte. Por ejemplo, con una subvención del año pasado limpiamos una serie de caminos que vale para los ganaderos y vale también para los senderistas, pero igual si vamos hoy ya está cerrado otra vez, es decir que igual necesita mucho mantenimiento y el Ayuntamiento no puede 
asumirlo [...] es que todo eso se hace con dinero, si el Ayuntamiento tuviese mucho evidentemente estaría todo limpio, yo tengo dos obreros y no damos abasto solamente con limpiar el casco urbano (Víctor Arroyo, 2005).

Valdría la pena no olvidar la paradoja de que, mientras la actividad ganadera es la que define en gran parte el paisaje cultural actual, los jóvenes hombres y mujeres, ganaderos o de otras profesiones, no están involucrados en actividades que permitan afrontar las demandas y exigencias económicas y productivas actuales, de tal forma que la ganadería no se convierta en una actividad residual o meramente testimonial en aras del turismo, sino que se complemente con éste. Tal como señalan Cánoves Valiente y Villarino Pérez:

El cultivo de las tierras, el mantenimiento de las explotaciones, la conservación de los edificios rurales es parte del patrimonio cultural. Sin vida en el territorio no hay atractivo turístico, y la conservación del territorio pasa por ofrecer a sus habitantes alternativas económicas en el medio rural (Valiente y Pérez, 2002: 70).

\section{Consideraciones finales}

Para concluir nos permitimos señalar que, en el caso de Vega de Pas, tal vez sería tarea de las administraciones públicas no sólo organizar sino involucrar real y activamente a los distintos actores (pasiegos del casco y ganaderos de los barrios) de manera que pudieran participar en los deseos y decisiones de patrimonialización. Es decir, que el "despegue de la conciencia patrimonial", como diría Hernández (2003: 4), también los alcance a ellos, pues los bienes patrimoniales no poseen en sí mismos valor simbólico o identitario, sino que son revalorizados y resignificados a través de la selección y el reconocimiento de las colectividades; más aún, cuando la Consejería de Medio Ambiente tiene entre manos el proyecto de la declaración de la zona como Patrimonio de la Humanidad. ${ }^{12}$
Este proyecto para nada carece de importancia, pues de esta patrimonialización y de otras se espera una rentabilidad económica, como claramente se manifiesta en los discursos europeos y regionales de desarrollo rural, local, sostenible y, en estas circunstancias, entre más plurifuncional se vuelve el medio rural, más posibilidades surgen para todos los que lo habitan; como señala Arantes (1984), tanto los espacios como las prácticas y otros bienes van siendo retirados del flujo de la vida cotidiana, se reúnen, resignifican, recontextualizan y participan de la dinámica de la cultura que crean y recrean los organismos públicos de preservación.

A su vez, queda también evidenciado cómo los nuevos arreglos y políticas económicas expresadas por la Unión Europea en España han propiciado un rejuego de poder económico cuyo resultado es la polarización y la generación de mayores presiones a la ganadería de Alta Montaña. Destaca la incorporación de Vega de Pas en la economía global y el proceso de reestructuración de su aparato productivo bajo fuertes efectos y tensiones socioeconómicas en el nivel local.

Estas situaciones provocan la construcción de un nuevo campo para el quehacer de la globalización por parte de los ganaderos pasiegos: la patrimonialización de su paisaje con fines de comercialización turística en beneficio de su comunidad, en el que estos actores den forma y doten de especificidad los macroprocesos que se han impuesto a través de sus acciones de transformación, envueltas en nuevas ideas y significados.

\section{Notas}

${ }^{1}$ El presente artículo se desprende del trabajo general desarrollado durante la estancia académica doctoral que los autores realizaron en España durante 2002 y 2003 y hasta 2006.

${ }^{2}$ Cesto grande y hondo, de sección cuadrangular, más ancho por su boca que por el fondo, utilizado tradicionalmente por los pasiegos y pasiegas para el transporte 
El paisaje Cultural COMO ELEMENTO dE

Patrimonialización: el Caso de Vega de Pas,

de todo tipo de cosas, actualmente se utiliza sobre todo para hierba, leña y, algunas veces, alimentos.

${ }^{3}$ Suecos de madera con tres tacos en la planta, utilizados para evitar la humedad del suelo.

${ }^{4}$ En Vega se puede encontrar actualmente una nave lechera que comercializa la leche como materia prima con la empresa Kaiko, uno de los principales centros lecheros de la región.

5 Actividad económica principal - fuera de la ganadería- que en su momento, estamos hablando de hasta el último tercio del siglo pasado, desempeñaban los pasiegos en distintos contextos sociales ajenos al suyo, como fueron los casos conocidos de su migración a Francia o a Andalucía, España; y que ahora fue desplazada por la construcción.

${ }^{6}$ Tal como los denomina Juan G. Atienza en su Guía de los pueblos malditos españoles, colección Guías de la España insólita, Ariel, Barcelona, España, 1985. Puede verse también García-Egocheaga, Javier, Minorías malditas. La historia desconocida de otros pueblos de España, Tikal, Madrid, s/f.

${ }^{7}$ En este caso por ejemplo, entre los pasiegos la "modernidad" rural es una actitud no explícita. Es un deseo de la población de no seguir siendo como aquellos individuos que les precedieron; es el inicio de otra etapa articulada a la globalización. Sin embargo, esta "modernidad" que se vive no llega a ser una ruptura total con las "tradiciones", sino una refuncionalización de una vieja coexistencia. La "modernidad" es un proceso violento con miras a un futuro incierto.

${ }^{8}$ Se refiere a los corderos pequeños.

${ }^{9}$ El Proder 1996-1999 o Proder I, se aplicó en las zonas de las diez regiones españolas tipificadas por la política regional comunitaria como "Objetivo l". Una segunda fase de este programa conocida como PRODER 2 inicia su aplicación a partir del Marco Comunitario de Apoyo 2002-2006. En la Comunidad Autónoma de Cantabria se conoce como Prodercan. A diferencia de la primera fase, alcanza a todo el territorio nacional, afectando tanto a las zonas y comarcas de regiones que estén incluidas entre las más necesitadas de ayudas estructura- les por sus problemas de desarrollo (Objetivo 1) como a aquéllas que se encuentren en situación transitoria hacia el Objetivo 2, como es ahora el caso de la Comunidad Autónoma de Cantabria, e incluye a las que estén situadas en las regiones de Objetivo 2.

${ }^{10}$ Productos de origen pasiego. Aunque en la actualidad su fabricación se ha extendido a casi toda Cantabria, siguen siendo conocidos en toda España como emblemáticos de la gastronomía de la comarca pasiega.

${ }^{11}$ Aunque, por otro lado, algunas opiniones son contrarias a este proceso. El alcalde Víctor Arroyo, por ejemplo, pone de manifiesto los problemas que esto ocasiona al Ayuntamiento ya que los nuevos propietarios exigen unos servicios que el Ayuntamiento no puede asumir porque es muy pequeño: “ [...] como los de afuera prefieren comprar donde existan facilidades de acceso, entonces los propietarios, los de aquí quieren exigir arreglo de las vías y caminos con objetivo de vender, no para que le sirva a él sino sólo con el objetivo de vender. Se puede tramitar dinero de la Consejería de Ganadería por ejemplo, pero es para favorecer las praderas, hacer una pista pero para favorecer a la gente que trabaja el campo de verdad y necesita las vías; pero no para vender (...) y menos a unos de afuera que encima van a venir y exigir que hay piedras, que está mal y que hay que asfaltarlo porque es un señor de la ciudad que quiere venir aquí con las comodidades de la ciudad, eso no se puede, no te creas que es mucha ganancia para el pueblo" (Vega de Pas, 2005).

${ }^{12}$ Según declaración hecha por el Consejero del Medio Ambiente del Gobierno de Cantabria, José Ortega V., para El Diario Montañés del 27 de mayo de 2005, publicada con el título "Medio Ambiente ve una posible amenaza de desaparición de los valles pasiegos".

\section{Bibliografía}

Arantes, Antonio, 1984, Produzindo o pasado, editorial Brasiliense, Sao Paulo.

Atienza, Juan G., 1985, Guía de los Pueblos Malditos de España, editorial Arín, Barcelona. 
Bourdieu, Pierre, 1999, ¿Qué significa hablar? Economía de los intercambios lingüísticos, Ediciones Akal, Madrid.

-, 1999, Meditaciones Pascalianas, Anagrama, Barcelona.

Cantabria 102 municipios, 2004, Editorial El Diario Montañés, Consejería de Cultura, Turismo y Deporte, Gobierno de Cantabria/Caja Cantabria Obra Social, Santander.

Cánoves V., Gemma y Montserrat Villarino P., 2002, “Turismo en espacio rural en España: actrices e imaginario colectivo", en documento, Análisis Geográfico, número 37, http://www.bib.uab.es., pp. 51-77.

Castells, Manuel, 2003, La era de la información. El poder de la identidad, Alianza, vol. 2, segunda edición, Madrid.

Delgado Viñas, Carmen, 2003, Los Montes de Pas. Realidad presente y expectativas de futuro, Universidad de Cantabria, Consejería de Ganadería, Agricultura y Pesca, Gobierno de Cantabria, Santander.

Flores, Elena, 2003, Estudio de ecología humana en la Comunidad Pasiega/Cantabria, Centro de Documentación Etnográfica sobre Cantabria, Santander.

García Lomas, Adriano, 2002, Los Pasiegos, Ediciones Librería Estudio, Biblioteca Cantabria, vol.16, Santander.

Giddens, Anthony, 1995, "La experiencia secuestrada", en Modernidad e identidad del yo. El ego y la sociedad en la época contemporánea, Península, Barcelona.

Gobierno de Cantabria, 2005, Plan de Gobernanza Informa, Publicación informativa del Plan de Gobernanza, núm. 5, Cantabria.

Godelier, Maurice, 1998, Elenigma del don, Paidós, Barcelona.

Gómez Pellón, Eloy y M. A. Sánchez Gómez, 2003, Los Pasiegos, Universidad de Cantabria, Ayuntamiento de Torrelavega.

Hernández R., Javier, 2003, "El patrimonio en movimiento. Sociedad, memoria y patrimonio", en Revista Mexicana de Estudios Antropológicos, tomo XLIII, México.

Ibáñez Martínez-Conde, Juan, 1990, El valle de Pas: Sin salida al mar, Universidad de Cantabria, Santander.

Instituto Nacional de Estadística (INE), 2004, Censo de Población 2001-2003, Gobierno de Cantabria, Santander.
Leal, Arnaldo, 199la, De Aldea a Villa. Historia Chica de las Tres Villas Pasiegas, Asociación Científico Cultural de Estudios Pasiegos, Museo de las Villas Pasiegas, Vega de Pas, Cantabria.

—, 1991b, Los pasiegos: colonización del entorno y conquista de una dignidad, Asociación Científico Cultural de Estudios Pasiegos, Museo de las Villas Pasiegas, Vega de Pas, Cantabria.

Menéndez L., Eduardo, 2002, La parte negada de la cultura. Relativismo, diferencias y racismo, Balleterra, Barcelona.

Naredo, Juan Manuel, 2004, La agrícultura en España (1940-2000), Universidad de Granada, cuarta edición, Granada.

Narotzky, Susana, 2004, Antropología económica. Nuevas tendencias, Melusina, Barcelona.

Ortega Valcárcel, José, 1975, "Organización del espacio y evolución técnica en los Montes de Pas”, en Estudios Geográficos, Homenaje a Manuel de Terán, Instituto "Juan Sebastián Elcano", núm. 140-141, vol. XXXVI, Madrid.

Puente Fernández, Leonor De La, 2002, "Desarrollo rural y ordenación del territorio en Cantabria", en Libro Blanco de la Agricultura y el Desarrollo Rural, ponencia presentada en la Jornada Autonómica de Cantabria, Santander, 10 de octubre de 2002, pp.1-35.

Tax Freeman, Susan, 1975, "Pasiegos y pasieguería. Estudio de historia e historiografía provincial", en Publicaciones del Instituto de Etnografía y Folklore "Hugo Sainz", vol. VII, Institución Cultural de Cantabria, Diputación Provincial de Santander.

—, 1979, The pasiegos: spaniards in no man's land, University of Chicago Press, Chicago.

Terán, Manuel, 1947, "Vaqueros y cabañas en los Montes de Pas", en Estudios Geográficos, Instituto "Juan Sebastián Elcano”, núm. 28, año VII, Madrid.

Zamora, Elías, 1994, "Sociedad local y sistemas mundiales: el papel de la cultura en el desarrollo territorial", en VV. AA.: La Fundación de la Cultura en el Desarrollo Local, Diputación Provincial de Córdoba, pp. 21-31. 